\title{
EVALUASI PERFORMANCE REGENERASI MIXED BED POLISHER PADA UNIT DEMINERALISASI
}

\author{
Irhamni Nuhardin $^{1^{*}}$, Mimin Septiani ${ }^{2}$, Ronaldo Rivaldiansyah ${ }^{3}$ \\ ${ }^{1,2,3}$ Sekolah Tinggi Teknologi Industri Bontang, \\ *irhamni.in@gmail.com
}

\begin{abstract}
Abstrak
Salah satu elemen penting yang dihasilkan dari unit penunjang pabrik adalah produk air. Water balance kawasan (integrasi) merupakan hal penting untuk menjamin kelangsungan operasional pabrik. Raw water diolah pada bagian unit untuk menghasilkan air demin dan di proses lebih lanjut menjadi Boiler Feed Water (BWF) untuk menghasilkan steam bertekanan $80 \mathrm{~kg} / \mathrm{cm}^{2}$ pada unit boiler, untuk memenuhi spesifikasi sebagai air demin maka perlu dilakukan beberapa treatment untuk menghilangkan ion-ion mineral (kation dan anion) yang terlarut dalam air. Dalam mixed bed polisher terdapat proses regenerasi resin untuk menghilangkan kejenuhan pada resin yang sudah tidak dapat mengikat ion mineral kembali. Regenerasi atau regent dilakukan setelah tumpukan resin jenuh yang ditandai dengan naiknya konduktivitas produktivitas produk dengan target konduktivitas produk yang diinginkan yaitu sebesar $<0,2 \mu \mathrm{S} / \mathrm{cm}$ pada suhu $25^{\circ} \mathrm{C}$. Tujuan dari penelitian ini adalah untuk mengevaluasi kinerja atau performa mixed bed polisher khususnya pada saat regenerasi pada unit demineralisasi. Penelitian ini dilakukan dengan cara penentuan kerangka pemikiran dan tahapan penulisan. Tahapan penulisan berisi pengumpulan data, pengolahan data dan analisissintesis data, serta pengambilan kesimpulan. Berdasarkan penelitian ini maka diperoleh hasil bahwa terjadi penurunan performance dari mixed bed dengan perolehan bed expansion sebesar $80,7 \%$ dan tinggi resin 2,42 m. Banyaknya bahan kimia yang digunakan untuk regenerasi adalah $1170,7 \mathrm{~kg}$ yang terdiri dari HCL dan $\mathrm{NaOH}$ sehingga flow rate air demin yang dibutuhkan untuk mengencerkan regeneran adalah $7.126 \mathrm{~m}^{3} / \mathrm{h}$.
\end{abstract}

Kata kunci: Mixed bad Polisher, Air demin, Regenerasi resin.

\begin{abstract}
One of the important elements produced from the factory support units is air products. Regional water balance (integration) is important to support factory operations. Raw water is treated in the unit section to produce demin water and further process into Boiler Feed Water (BWF) to produce $80 \mathrm{~kg} / \mathrm{cm}^{2}$ pressurized steam in the boiler unit, to meet the specifications as demin water it is necessary to carry out several treatments to remove mineral ions (cations and anions) dissolved in the air. In the mixed bed polisher, there is a resin regeneration process to eliminate saturation of the resin which can no longer bind mineral ions. Regeneration or regent is carried out after the resin pile is saturated which is characterized by an increase in product productivity conductivity with the desired product conductivity target of $<0.2 \mu \mathrm{S} / \mathrm{cm}$ at a temperature of $25^{\circ} \mathrm{C}$. The purpose of this study was to work or perform a mixed bed polisher, especially during regeneration in the demineralization unit. This research was conducted by making a framework of thought and writing work. The writing stage contains data collection, data processing and data analysis-synthesis, as well as drawing conclusions. Based on this research, the results showed that there was a decrease in the performance of the mixed bed with a bed expansion gain of $80.7 \%$ and a resin height of $2.42 \mathrm{~m}$. The number of chemicals used for regeneration is $1170.7 \mathrm{~kg}$ consisting of $\mathrm{HCL}$ and $\mathrm{NaOH}$ so that the flow rate of demin water required to dilute the regenerant is $7,126 \mathrm{~m}^{3} / \mathrm{h}$.
\end{abstract}

Keywords: Mixed bad Polisher, Demin water, Resin regeneration. 


\section{PENDAHULUAN}

Kaltim Daya Mandiri (KDM) adalah perusahaan utilitas dan energi yang didirikan dengan tujuan untuk menyuplai kebutuhan utilitas pada fasilitas produksi pabrik PT Pupuk Kaltim serta perusahanperusahaan lain yang berada di lingkungan Kaltim Industrial Estate. Salah satu elemen penting yang dihasilkan dari unit penunjang pabrik adalah produk air. Water balance kawasan (integrasi) merupakan hal penting untuk menjamin kelangsungan operasional pabrik. Raw water diolah pada berbagai unit untuk menghasilkan air demin dan diproses lebih lanjut menjadi Bolier Feed Water (BFW) untuk menghasilkan steam bertekanan $80 \mathrm{~kg} / \mathrm{cm} 2$ di unit Boiler, untuk memenuhi spesifikasi sebagai air demin maka perlu dilakukan beberapa treatment untuk menghilangkan ion- ion mineral (kation dan anion) yang terlarut dalam air.

KDM menggunakan treatment mixed bed polisher yang mencampurkan resin penukar kation dan resin penukar anion dalam satu bed. Umpan mixed bed berasal dari tanki air Raw Condensat yang berasal dari unit desalinasi PT Pupuk Kaltim dan tanki Air T-404 yang berasal dari SWRO Plant KDM. Pada kondisi normal satu mixed bed polisher running dan satu stand by. Mixed bed dijaga pada kondisi normal untuk menjaga ketersediaan air demin sehngga water balance positif, oleh karena itu perlu pengamatan kondisi operasi mixed bed agar bisa dideteksi sedini mungkin jika terjadi penyimpangan dari kondisi normal.

Dalam mixed bed polisher terdapat proses regenarasi resin untuk menghilangkan kejenuhan pada resin yang sudah tidak dapat mengikat ion mineral kembali. Re generasi atau Regent dilakukan setelah tumpukan resin jenuh yang ditandai dengan naiknya konduktivitas produk dengan target konduktivitas produk yang diinginkan adalah sebesar $<0,2 \mu \mathrm{S} / \mathrm{cm}$ pada Suhu $25^{\circ} \mathrm{C}$.

Pengamatan secara global menemukan beberapa kendala pada pengoperasian mixed bed yaitu, lolosnya resin pada saat regenerasi step backwash. Kenaikan konduktivitas produk demin mixed bed yang berlangsung cepat sehingga harus sering diregenerasi. Berbagai masalah hasil pengamatan perlu dianalisis faktor peyebabnya disertai rekomendasi singkat sebagai dasar untuk perbaikan. Penelitian ini memfokuskan dalam menganalisa penyebab terjadinya penyimpangan dari desain alat dengan mengamati kondisi operasi dari berbagai sumber terutama log sheet operator. Data yang diperoleh kemudian dibandingkan dengan desain alat, perbedaan yang dijadikan dasar untuk telaah pembahasan berdasarkan teori dasar dari berbagai referensi. Tujuan pelaksanaan penelitian ini adalah untuk mengevaluasi kineja atau performa mixed bed polisher terutama saat regenerasi pada unit demineralisasi PT. KDM.

\section{Tinjauan Teori}

Mix Bed Polisher (MBP) merupakan unit untuk memproduksi air demin. Air demin merupakan air yang tidak memiliki kandungan mineral. Kandungan mineral dalam air demin dijaga seminimal mungkin dengan parameter konduktivitas air demin dibawah $0,2 \mu \mathrm{S} / \mathrm{cm}$. Air demin produksi Unit MBP di PT Kaltim Daya Mandiri digunakan untuk air umpan unit HRSG dan sebagian diekspor ke Integrasi PT Pupuk Kalimantan Timur dan PT Kaltim Nitrat Industri.

Air umpan unit MBP yang akan dijadikan air demin berasal dari air desalinasi dan air kondensate dari pemakaian steam (raw condensate). Air desalinasi diperoleh dari unit SWRO KDM dan raw condensate yang berasal dari impor PT Pupuk Kalimantan Timur. Kapasitas unit MBP KDM sebesar 2 x 168 m3/h. Unit MBP berisi dengan resin yang dapat mengikat ion-ion positif dan negatif dari air desalinasi yang memiliki konduktivitas sekitar $12 \mu \mathrm{s} / \mathrm{cm}$. Air demin disimpan dalam tangki penyimpanan dengan kapasitas $2000 \mathrm{~m}^{3}$. 
Proses service yaitu dimana air umpan dilewatkan kedalam vessel berisi Resin Anion dan Resin Kation yang tercampur secara homogen sehingga ionion yang terkandung dalam air umpan akan tertangkap dan bereaksi dengan resin. Air umpan berupa air desalinasi diumpankan dari atas vessel dan produk air demin akan keluar melalui distributor yang ada di bawah tangki.

Fungsi distributor adalah agar terbentuk aliran yang homogen. Distributor terdapat pada tiga tingkatan yaitu di bawah, tengah, dan atas. Distributor bawah terletak di paling dasar tumpukan resin, berfungsi untuk membentuk aliran produk atau umpan yang merata saat proses service dan juga untuk membentuk aliran $\mathrm{HCl}$ yang merata saat proses regenerasi. Distributor atas terletak di paling atas dari tumpukan resin, berfungsi untuk membentuk aliran $\mathrm{NaOH}$ yang merata saat proses regenerasi. Distributor tengah berfungsi untuk membentuk aliran bahan kimia sisa regenerasi yang merata keluar dari tangki.

Resin kation berfungsi untuk menghilangkan kation seperti natrium, kalsium dan magnesium dengan menggantikan kation tersebut dengan ion hidrogen yang ada di resin cation exchange. Resin anion berfungsi menghilangkan anion seperti klorida, sulphate, silica dan bicarbonate dengan menggantikan anion tersebut dengan ion hidroksida yang ada di resin anion exchange. Ada 2 unit mixed bed polisher dengan kapasitas masingmasing sebesar $168 \mathrm{~m} 3 / \mathrm{jam}$. Satu mixed bed polisher akan beroprasi dan satu mixed bed polisher lainnya standby. Apabila mixed bed polisher yang beroperasi jenuh, maka yang standby akan dioperasikan dan yang jenuh akan diregenerasi. Siklus service/operasi ditentukan berdasarkan konduktivitas produk $0,2 \mu \mathrm{S} / \mathrm{cm}$.

Resin dalam proses produksi air demin memerlukan regenerasi saat terjadi kejenuhan. Karena Resin Kation dan Resin Anion tercampur dalam sebuah vessel, maka proses regenerasi memiliki beberapa tahapan yang harus dilakukan agar proses regenerasi berjalan optimal. Secara umum tahapan proses dapat dilihat dalam gambar di bawah :

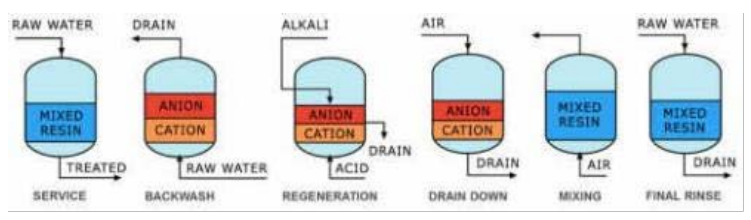

Gambar 2. Proses Service dan Tahapan Regenerasi Unit Mix Bed Polisher

Automatic dumping (blowdown) untuk mixed bed polisher terjadi ketika kondutivitas produk lebih tinggi dari nilai settingan. Settingan automatic dumping adalah pada kondutivitas produk 0,5 $\mu \mathrm{S} / \mathrm{cm}$. Target kualitas produk yang dimonitor adalah konduktivitasnya sebesar $0,2 \mu \mathrm{S} / \mathrm{cm}$ pada $25^{\circ} \mathrm{C}$.

\section{METODE PENELITIAN}

Metode penelitian ini terdiri dari penentuan kerangka pemikiran dan tahapan penulisan. Tahapan penulisan berisi pengumpulan data, pengolahan data dan analisis-sintesis data dan pengambilan kesimpulan. Studi pustaka bertujuan untuk mendapatkan data teoritik atau referensi yang berhubungan dengan penelitian mengenai operasi Mixed Bed Polisher. Sumber yang digunakan berupa $P \& I D$, jurnal hasil penelitian, serta spesifikasi resin dari vendor. Monitoring bertujuan untuk mengamati dan memperoleh data operasi berupa log sheet, laporan kepala shift serta laporan bulanan. Selanjutnya data akan diolah untuk mendapat kesimpulan dari permasalahan yang diangkat dalam tugas khusus ini. Kajian data penelitian bertujuan untuk mengetahui sejauh mana arah batasan pembahasan dari subjek penelitian yang diangkat dalam penelitian ini yaitu Mixed Bed Polisher.

Data sekunder yang diperoleh dari proses pengumpulan data diolah kemudian dirancang dan dilakukan proses perhitungan untuk mendapatkan data-data 
yang relevan dengan kajian tulisan serta mendukung uraian atau analisis pembahasan. Pemilihan dan pengelolaan data dengan tema sangat penting karena mempengaruhi pengambilan kesimpulan dan rekomendasi. Pada proses pengelolaan data lebih diutamakan data yang berasal dari proses monitoring, basic design, dan jurnal ilmiah hasil penelitian. Analisis sintesis bertujuan untuk menggali segala kemungkinan penyebab masalah. Kemudian dilakukan transfer gagasan untuk mencari faktor penyebab terjadinya masalah dan rekomendasi yang mengacu pada referensi dan data yang telah dikumpulkan. Objek yang akan diteliti pada tugas khusus ini adalah Mixed Bed Polisher pada unit demineralisasi PT Kaltim Daya Mandiri (V-01 A/B). Variabel penelitian berupa kondisi operasi yaitu parameterparameter penting dalam pengoperasian dan regenerasi Mixed Bed Polisher.

\section{HASIL DAN PEMBAHASAN}

Untuk mengetahui performance mixed bed maka dilakukan pengukuran konduktivitas produk demin di header mixed bed dan di demin storage tank (T06) discharge pompa demin transfer (P-03 $\mathrm{A} / \mathrm{B})$ ke deaerator. Pengukuran nilai konduktivitas yang dilakukan oleh laboratorium hanya dilakukan dalam jangka seminggu sekali setiap hari rabu. Grafik 1 dibawah ini menyajikan pengukuran konduktivitas pada discharge pompa demin transfer pada bulan Januari 2020 sampai bulan Juni 2020.

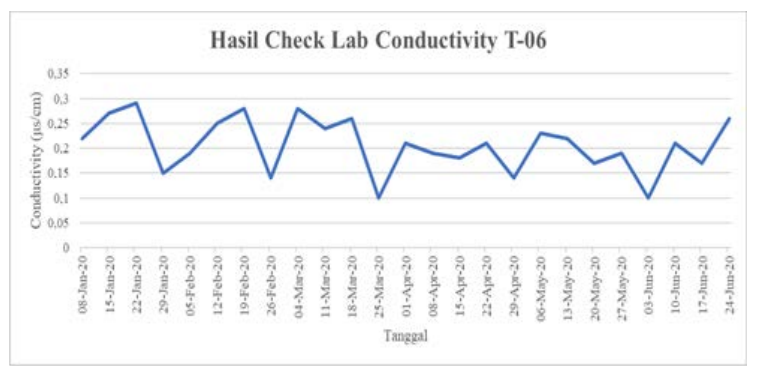

Grafik 1. Analisa Konduktivitas T-06 oleh Laboratorium
Dari hasil analisa laboratorium dapat diketahui bahwa produk demin KDM ratarata masih jauh dibawah batasan yang diijinkan yaitu maksimal $2 \mu \mathrm{S} / \mathrm{cm}$. Konduktivitas air merupakan ukuran kemampuan air dalam menghantarkan arus listrik (Erlina dan Budi, 2007). Oleh karena itu dengan mengetahui besaran konduktivitas akan diperoleh gambaran/perkiraan kadar ion-ion yang terlarut dalam air. Demineralisasi air sangat penting untuk meminimalisasi kandungan ion-ion yang terlarut dalam air demin sebagai umpan boiler setelah dihilangkan kandungan oksigennya dan diatur pH-nya.

Konduktivitas air yang tinggi dapat menyebabkan terbentuknya kerak pada dinding boiler akibat adanya mineralmineral pembentukan kerak, misalnya ionion kesadahan seperti Ca2+ dan Mg2+. Jenis-jenis kerak yang umum dalam boiler adalah kalsium sulfat, senyawa silikat dan karbonat. Zat-zat dapat membentuk kerak yang keras dan padat sehingga bila lama penanganannya akan sulit sekali untuk dapat dihilangkan. Silika mengendap bersama dengan kalsium dan magnesium sehingga membuat kerak semakin keras dan semakin sulit untuk dihilangkan. Kerak yang menyelimuti permukaan boiler dan menunjukan dua akibat utama yaitu berkurangnya panas yang dipindahkan ke air sehingga dapat meningkatkan temperatur material dan menurunnya efisiensi boiler.

Untuk mengurangi terjadinya pembentukan kerak pada boiler biasanya dilakukan pencegahan-pencegahan sebagai berikut:

1. Melakukan blowdown secara teratur jumlahnya

2. Memberikan bahan kimia anti kerak.

3. Pasivasi material boiler dengan oksigen dan pengatur $\mathrm{pH}$.

Efek lebih spesifik akibat dari indikasi konduktivitas yang tinggi pada air demin adalah caustic embrittlement atau keratakan inter kristalin pada baja. Caustic embrittlement terjadi pada tekanan tinggi 
dan lingkungan kimia yang tidak sesuai. Peristiwa ini biasanya terjai pada sambungan dan meluas pada ujung-ujung drum dimana memungkinkan pembentukan lingkungan caustic yang terkonsentrasi. Oleh karena itu produk demin harus dijaga pada range operasi untuk menghindari terjadinya kerusakan- kerusakan di unit dengan tekanan dan temperatur tinggi. Pemantauan juga dilakukan untuk meninjau kinerja dari mixed bed dengan mencatat data konduktivitas produk mixed bed dengan nomor item analizer AIC-402/403 yang dapat terbaca di local control panel. Data hasil pemantauan disajikan dalam bentuk grafik untuk memudahkan pembacaan seperti Grafik 2 berikut.

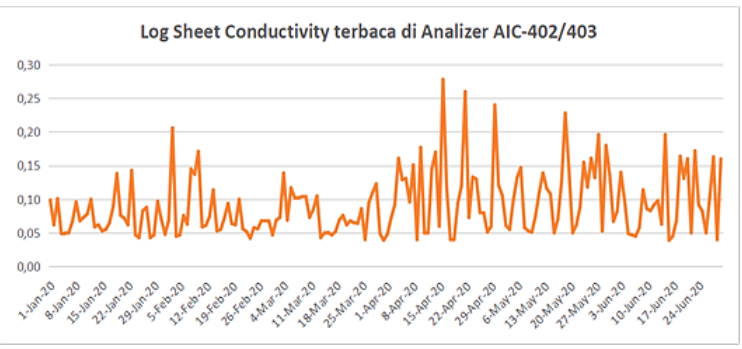

Grafik 2. Konduktivitas terbaca di Analizer AIC-402/403

Grafik diatas menunjukan bahwa indikasi regenerasi dilakukan pada saat analizer menunjukan konduktivitas 0,2 $\mu \mathrm{S} / \mathrm{cm}$. Grafik inilah yang dijadikan patokan operator untuk regenerasi mixed bed karena data ini diambil dari analisa online. Sedangkan data dari laboratorium yang notabene lebih valid hanya disampling seminggu sekali sehingga tidak dapat dijadikan patokan untuk regenerasi.

$$
\text { Namun setelah tercapai }
$$

konduktivitas $0,2 \mu \mathrm{S} / \mathrm{cm}$ mixed bed tidak langsung diregenerasi, melainkan di lakukan step airmix kembali untuk menambah nilai total flow untuk kemudian kembali di-onlinekan. Re-airmix berfungsi untuk mengaduk resin sehingga pertukaran ion pada resin yang belum jenuh akan lebih optimal, hal ini disebabkan karena channeling yaitu buruknya distribusi air didalam vessel yang disebabkan oleh flowrate yang terlalu rendah.
Produksi dan operasi mixed bed sangat dipengaruhi oleh ketersedian air. Jika dalam kondisi krisis air maka didahulukan untuk menaikan level tanki untuk menjamin ketersediaan air proses. Kondisi ini mengharuskan mixed bed bekerja diluar kondisi desain dan produk yang dihasilkan juga memiliki konduktivitas yang lebih tinggi dari desain. Sehingga salah satu faktor yang secara langsung memengaruhi produksi air demin adalah kapasitas tanki. Kapasitas demin water tank adalah $2000 \mathrm{~m} 3$ dan overflow pada level 8,7 meter (tinggi tanki 9,14 meter).

Pada saat level air DW tank tinggi atau pada saat boiler shutdown maka produksi air demin dikurangi atau diseimbangkan dengan flowrate yang keluar dari DW tank dengan cara mengurangi flowrate inlet mixed bed yang service. Kasus ini terjadi pada saat pemantauan tanggal 10 Maret. Berikut data flow produk demin mixed bed bulan Januari 2020 sampai bulan Juni 2020.

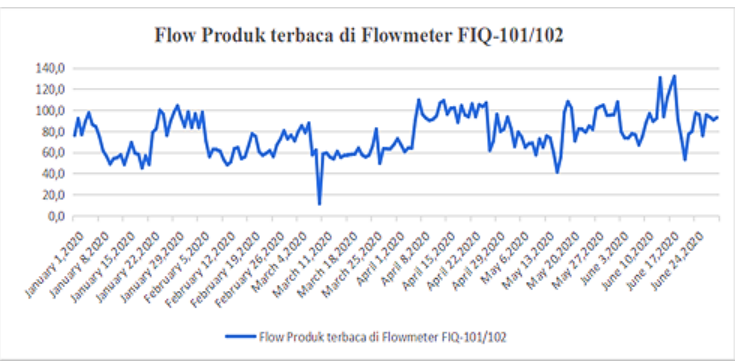

Grafik 3. Flow Produk terbaca di Analizer FIQ-101/102

Nampak pada grafik diatas rata-rata normal produksi mixed bed menyesuikan pemakaian air demin pada boiler dan ekspor, dengan produksi tidak melebihi kapasitas desain yaitu $168 \mathrm{~m} 3 / \mathrm{h}$. Pada kondisi normal satu mixed bed service dan satu mixed bed standby/regenerasi. Pada keadaan tertentu maka produksi dapat dikurangi dengan mengurangi atau diseimbangkan dengan mengatur flowrate mixed bed seperti pada pemantauan tanggal 1 Juni hingga 7 Juni. 
Faktor penyebab pengurangan produk mixed bed saat itu adalah level DW tank tinggi, sesuai data pada Grafik 4 berikut:

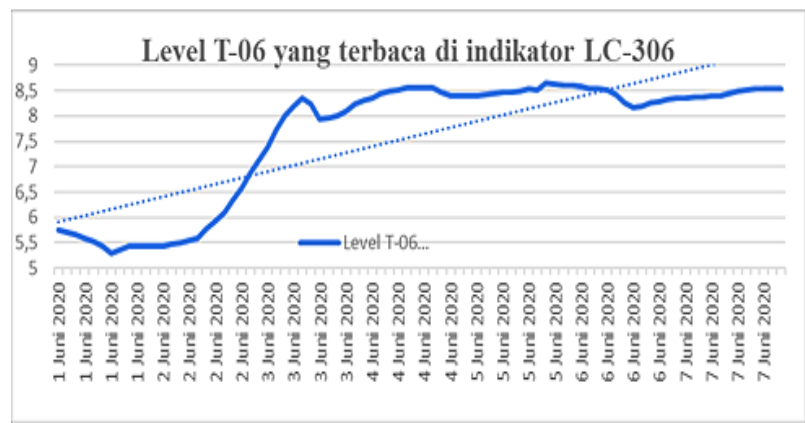

Grafik 4. Level T-06 yang terbaca di indikator LC-306

Parameter lain yang harus diperhatikan untuk mengoptimalkan kinerja mixed bed adalah kualitas air umpan. Kualitas umpan dapat dilihat dari beberapa parameter utama yaitu konduktivitas, $\mathrm{pH}$, dan suhu. Umpan mixed bed di Kaltim Daya Mandiri merupakan air yang berasal dari unit desalinasi SWRO KDM dan raw condensate yang berasal dari impor PT Pupuk Kalimantan Timur. Berikut merupakan grafik rata-rata nilai konduktivitas perhari umpan di inlet unit mixed bed berdasarkan pembacaan analizer AIC-401 selama bulan Juli 2020.

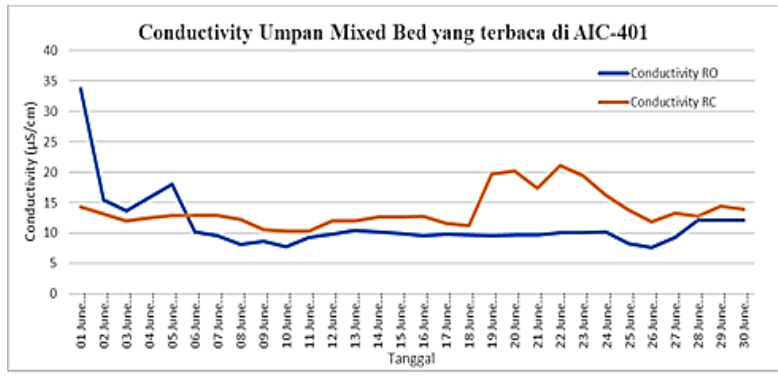

Grafik 5. Conductivity Umpan Mixed Bed yang terbaca di AIC-401

Gambar diatas menunjukan bahwa untuk parameter konduktivitas air umpan mixed bed di Kaltim Daya Mandiri secara rata-rata masih memenuhi standar yaitu dibawah $20 \mu \mathrm{S} / \mathrm{cm}$. Namun ditemukan beberapa kasus nilai konduktivitas melebihi ambang batas yang diperbolehkan, sehingga tingginya nilai konduktivitas umpan dapat mempengaruhi total flow mixed bed, hal ini dapat dilihat pada sekitaran awal bulan Juni 2020 dan di compare dengan total flow mixed bed. Tingginya nilai konduktivitas umpan dari RO plant biasanya disebabkan oleh penurunan nilai salt rejection sehingga perlu dilakukan Cleaning In Place (CIP), selain itu juga disebabkan oleh patah atau rusaknya interkoneksi antar membran didalam vessel RO, tingginya nilai konduktivitas umpan dari impor PT Pupuk Kaltim biasanya disebabkan oleh tercemar atau teracuninya tanki Raw Condensate. Kemudian parameter lain untuk air umpan akan dibahas di sub bab berikutnya.

$\mathrm{pH}$ merupakan salah satu indikasi performance resin mixed bed. Air umpan mixed bed jika diurai secara terpisah akan mengalami proses sebagai berikut. Saat melalui resin penukar kation, pengotor kation air akan dipertukarkan dengan $\mathrm{H}+$ sehingga air keluaran resin penukar kation bersifat asam. Sedangkan $\mathrm{pH}$ air ketika melalui penukar anion mengalami kenaikan. Hal ini disebabkan pada saat air melalui kolom resin penukar anion, anion pengotor air akan dipertukarkan dengan $\mathrm{OH}$ - dari resin penukar anion, sehingga terjadi pelepasan $\mathrm{OH}$ - oleh karena itu air setelah melewati kolom resin penukar anion mempunyai $\mathrm{pH}$ mendekati $\mathrm{pH}$ netral atau sedikit basa. Pada mixed bed pertukaran terjadi secara simultan sehingga air keluaran mixed bed mempunyai $\mathrm{pH}$ 5,86,5 .

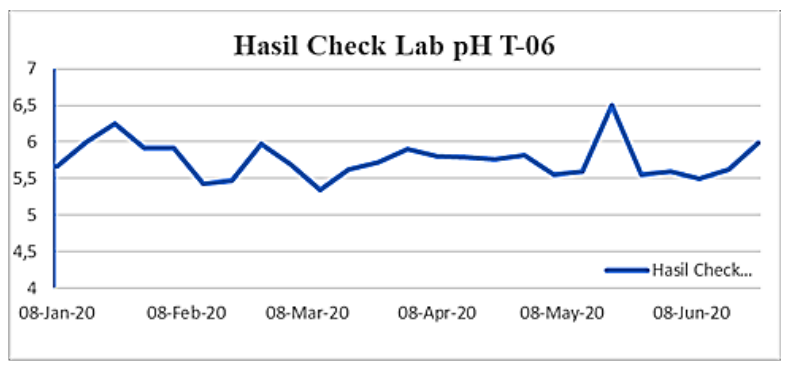

Grafik 6. Hasil Check Lab pH T-06 (produk mixed bed) 
Dari gambar 10 dapat diindikasi bahwa resin pada mixed bed Kaltim Daya Mandiri masih berfungsi dengan baik. Hal ini terlihat dari kualitas air produk mixed bed yang ditampung di DW Tank mempunyai $\mathrm{pH}$ sesuai range operasi. Namun untuk mengetahui performance resin dari masing-masing mixed bed polisher $\mathrm{A} / \mathrm{B}$, perlu ditinjau individual performance. Beberapa parameter yang dapat dijadikan indikasi adalah total flow seperti yang akan dibahas pada sub bab berikutnya.

Total flow untuk masing-masing mixed bed A dan B dapat dilihat dari grafik berikut ini.

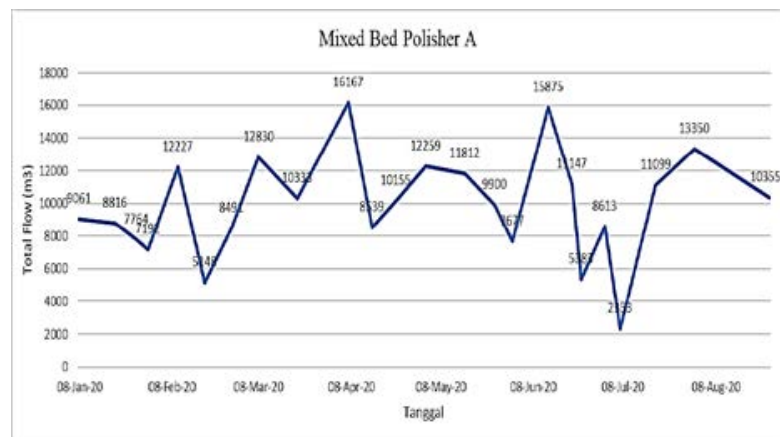

Grafik 7. Total Flow MBP A

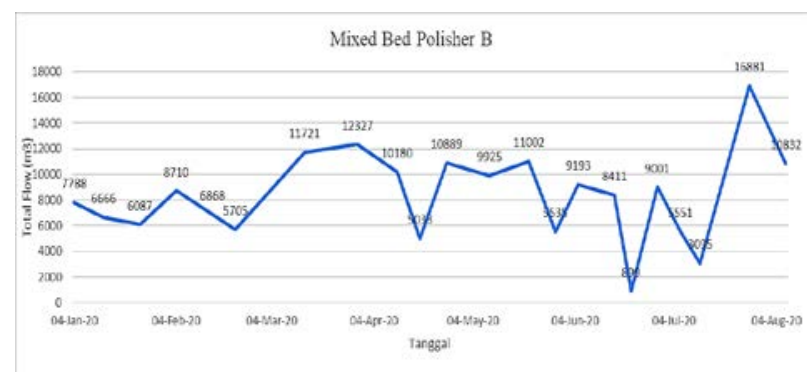

Grafik 8. Total Flow MBP B

Grafik diatas menampilkan nilai total flow masing-masing mixed bed dari bulan Januari 2020 sampai bulan Agustus 2020. Terjadi penurunan total flow yang cukup signifikan pada bulan Juli (MBP A) dan bulan Juni (MBP B) hal ini disebabkan karena kontaminasi disebabkan tingginya konduktivitas umpan yang diimpor dari Pupuk Kaltim, tingginya konduktivitas karena umpan yang terkontaminasi atau tercemar. Jika dibandingkan, Grafik 7 dan
Grafik 8 menunjukan bahwa total flow mixed bed B tidak sebanyak mixed bed A. Hal ini dapat menjadi indikasi bahwa terjadi penurunan performance dari mixed bed B. Rata-rata produksi selama bulan Januari 2020 hingga Agustus 2020 adalah sebesar $9225 \mathrm{~m} 3$ untuk mixed bed A dan 7315 m3 untuk mixed bed B. Nilai total flow yang lebih rendah pada mixed bed $\mathrm{B}$ menyebabkan cepatnya regenerasi, jika hal ini dibiarkan maka sama dengan pemborosan air RC dan chemical $\mathrm{HCl}$ dan $\mathrm{NaOH}$ untuk regenerasi. Sekali regenerasi membutuhkan air RC sebanyak $58 \mathrm{~m} 3$, air

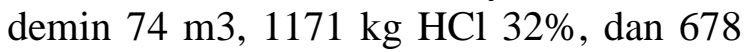
$\mathrm{kg} \mathrm{NaOH} \mathrm{48 \% .} \mathrm{Karena} \mathrm{umur} \mathrm{resin} \mathrm{mixed} \mathrm{B}$ yang masih cukup muda, maka rekomendasinya perlu dilakukan evaluasi terkait dozing saat regenerasi step chemical in, juga untuk menjaga kualitas umpan dari segala pencemar seperti tingginya conductivity yang akan mengurangi total flow mixed bed.

\section{KESIMPULAN}

Rata-rata produksi selama bulan Januari 2020 hingga Agustus 2020 adalah sebesar $9225 \mathrm{~m}^{3}$ untuk mixed bed A dan $7315 \mathrm{~m}^{3}$ untuk mixed bed B. Hal ini dapat menjadi indikasi bahwa terjadi penurunan performance dari mixed bed $B$. Berdasarkan perhitungan diperoleh bed expansion dengan persentase $80.7 \%$ dan tinggi resin 2.42 meter, nilai ini masih dibawah tinggi desain vessel yaitu 3 meter. Banyaknya bahan kimia yang digunakan untuk regenerasi adalah $1170.7 \mathrm{~kg}$ untuk $\mathrm{HCl} 32 \%$ dan $678 \mathrm{~kg}$ untuk $\mathrm{NaOH} 48 \%$, sedangkan dosis $\mathrm{HCl}$ sebesar 104.06 g per liter resin kation dan dosis $\mathrm{NaOH}$ sebesar 122.81 g per liter resin anion, diperoleh regeneration efficiency sebesar 92.5\% untuk kation dan 56.5\% untuk anion.

Diperoleh regeneration ratio sebesar $142.55 \%$ untuk resin kation dan 236.15\% untuk resin anion. Flow rate air demin yang dibutuhkan untuk mengencerkan regeneran adalah $7.126 \mathrm{~m}^{3} / \mathrm{h}$ untuk $\mathrm{HCl}$ dan $6.78 \mathrm{~m}^{3} / \mathrm{h}$ untuk $\mathrm{NaOH}$, 
sedangkan flow rate $\mathrm{HCl} 32 \%$ sebesar $1.018 \mathrm{~m}^{3} / \mathrm{h}$ dan flow rate $\mathrm{NaOH} 48 \% 0.452$ $\mathrm{m}^{3} / \mathrm{h}$.

\section{DAFTAR PUSTAKA}

Adhiatama, Irsan. 2014. Monitoring Kondisi Operasi Mixed Bed Polisher Kaltim-1. Bontang: PT Pupuk Kalimantan Timur.

Ariyanto, Dafid dan Handariansah.2016. Optimalisasi Produksi Mix Bed dengan penambahan reaming di PLTGU Tambak Lorong Semarang. Jurnal Presipitasi 13, 44-47.

Biyantoro, D. et.al., 2006. Studi Operasi Penukar Ion dalam Sistem Purifikasi Air Primer PWR. GANENDRRA IX, 1-8.

Budi, Utomo S., dkk., 2012. Analisis dan Pengendalian Konduktifitas Air pada Kolom Resin Campuran (Mix-Bed) Sistem Air Bebas Mineral (GCA 01)
Buletin Pengelolaan Reaktor Nuklir 9, 27-34.

Gumelar, Bagas R., \& Taufan M. 2017. Evaluasi Mixed Bed Polisher B Pada Unit Demineralisasi Departemen Operasi Pabrik-3. Bontang: PT Pupuk Kalimantan Timur.

François de Dardel. 2020. Regeneration methods for ion exchange units. Dardel IX - Ion Exchange Site. Informasi dari http://www.dardel.info/IX/processes/r egeneration.html (diakses pada: 5 Mei 2020).

Product Data Sheet AmberjetTM $4200 \mathrm{Cl}$. Industrial Grade Strong Base Anion Exchanger. Rohm and Haas. www.lenntech.com/DataSheets/Amberjet-4200-Cl-L. Informasi dari (diakses pada: 5 Mei 2020). 